\title{
Understanding the mechanism of food waste management by using stakeholder analysis and social network model: An industrial ecology perspective
}

\author{
Wanying $\mathrm{Xu}^{\mathrm{a}, \mathrm{b}}$, Chuanbin $\mathrm{Zhou}^{\mathrm{a}, *}$, Aixin $\mathrm{Cao}^{\mathrm{a}}$, Min $\mathrm{Luo}^{\mathrm{a}}$ \\ a State Key Laboratory of Urban and Region Ecology, Research Center for Eco-Environmental Science, Chinese Academy of Sciences, Beijing 100085, PR China \\ ${ }^{\mathrm{b}}$ Key Laboratory of Biofuels, Qingdao Institute of Bioenergy and Bioprocess Technology, Chinese Academy of Sciences, Qingdao, Shandong Province 266101, \\ PR China
}

\section{A R T I C L E I N F O}

\section{Article history:}

Received 30 August 2014

Received in revised form 4 June 2016

Accepted 7 June 2016

Available online 23 June 2016

\section{Keywords:}

Food waste management

Stakeholder analysis

Social network model

Mechanism

Industrial ecology

\begin{abstract}
A B S T R A C T
Household food waste accounts for the largest fraction of municipal solid waste and becomes an emerging issue in the biogeochemical cycle of urban ecosystem. Multiple stakeholders with varied characteristics are involved in the food waste management; moreover, they can throw great impacts on the material flow of urban waste, in an industrial ecology perspective. However, the internal mechanism of food waste recycling and composting, regarding the behavior and interaction of different stakeholders, is not clear in previous studies. In this research, recycling and composting potential of household food waste is studied by applying the methodology of stakeholder analysis and social network model. The interest, attitude, power and knowledge of different stakeholders and their social networks were examined by interviews, with the studied case of Beijing, China. Result shows the significant difference of multiple stakeholders' properties. The governmental department of municipal solid waste management has the highest power and maximum interest on food waste recycling, whereas the key players (both high power and maximum interest) located in the midstream and downstream of food waste recycling (utilization of compost) are lacking. In addition, the stakeholders, who easily collect accurate information on food waste recycling, are also the ones most willing to share the knowledge. However, the knowledge and information of most stakeholders are insufficient and inaccurate. The density, node and centrality of the social networks on food waste recycling and composting indicate that here were inefficient connection or disjoint between downstream stakeholders and up/midstream stakeholders, however the some key nodes, e.g. composting utilization stakeholders (fertilizer plants) and municipal solid waste management service companies, could contribute more to bridge the social networks of food waste management. Using the tools of stakeholder analysis and social network models can help in understanding the internal mechanism and the complexity of the material flows of urban ecosystem.
\end{abstract}

(c) 2016 Elsevier B.V. All rights reserved.

\section{Introduction}

With the rapid development of urbanization, municipal solid waste generation has been increasing and has become a major challenge for urban ecosystem management, particularly in overpopulated developing countries (Wang and Nie, 2001; Zhang et al., 2010; Wilson et al., 2012). There are 170.81 million tons of municipal solid waste, of which $60 \%$ is household food waste, is generated

Abbreviations: BC, betweenness centrality; CC, closeness centrality; DC, degree centrality; N, node of the social network; SA, stakeholder analysis; SNA, social network analysis.

* Corresponding author.

E-mail address: cbzhou@rcees.ac.cn (C. Zhou). and collected in China in each year (Zhang et al., 2010). Most of foodwaste was disposed into landfills and treated by incinerators, producing large amounts of contaminants and wasting considerable biomass resources (Kuo et al., 2008; Mor et al., 2006). Household food waste contains abundant organic carbon and nutrient and can be used as an ideal material for composting, however, nowadays it waste always contain a lot of non-biodegradable and even hazard fractions due to insufficient source separation of municipal solid waste (Wang and Nie, 2001; Tai et al., 2011), therefore, the value of food waste composting has been lowered. The social economic and environmental factors of food waste management should be concerned, if a clean and sustainable material flow of food waste is expected. Similar to other issues of biogeochemical cycles in urban ecosystem, the food waste management also involves multiple stakeholders, including governments, enter- 
prises; scientific research institutes, residents, farmers and so forth, and their behaviors are determined by their interests, attitudes, power and knowledge (Tai et al., 2011; Xu et al., 2015). Previous studies examined a lot of aspects on food waste treatment and management, however, these researches were mainly focused on the technical and policy marking issues (Kim and Kim, 2010; Beattie 2014), few of them discussed about the internal mechanism of different stakeholders in the food waste management system.

Stakeholder analysis (SA) and social network analysis (SNA) models were demonstrated as a useful approach to study the environmental \& resource management and public governance issues (Reed et al., 2009; Lienert et al., 2013). SA methodology first emerged as an approach for strategic management in the mid-1980's (Emshoff, 1980; Freeman, 2010). Furthermore, social network analysis model also showed its great potential to examine the behavior and interaction of multiple stakeholders. SNA model was first used to a fishing village in Norway, and the nodes and their relationships, rather than individuals, were emphasized in this study (Barnes, 1954). Harary (1969) improved the model by using the conceptual graph including nodes (points) and relationships(lines) between nodes. In recent years, SNA model were applied to study the natural resource management, such as water governance, marine ecosystem and food chains (Navia et al., 2010; Stein et al., 2011; Buzhdygan et al., 2012; Dell'Apa et al., 2013; Hicks et al., 2013), attempting to integrate this sociological tools into the interdisciplinary researches. In the early stage, the theory was mostly based on manual computations and drawings; in the 1990s, with the development of computer science, a higher visual degree was achieved and the visual matrix was used to portray the entire system network, enabling the studies not only on individual network properties, but also on full social network properties and the network structures. In the past, most studies concentrated on nondirection binary (Hicks et al., 2013; Navia et al., 2010; Yang and Zou, 2014). Currently, attention is turning to the direction of assignment value study (Buzhdygan et al., 2012; Dell'Apa et al., 2013; Lienert et al., 2013). However, only a few of works studied the waste management issues by applying SA and SNA methods. Caniato et al. use this tool to analyze the construction of a medical wasteincineration project (Caniato et al., 2014; Caniato et al., 2015). Xu et al. (2015) studied the issue on community-based source separation by applying SA model, and put forward implications of incentive policies. Xu et al. (2016) studied the stakeholders of a household food waste source separating program, but go into the detail models of different stakeholders. However, more efforts in this field are worthy to be taken, because it is not only valuable for understanding the mechanism and complexity of human dominated urban ecosystem, but also useful for who make policies and implement sustainable waste management programs.

In this research, SA and SNA models are integrated to study the potential of starting up a food waste recycling and composting program in Beijing, China. The interest, power, attitude and knowledge of twenty-three categories of related stakeholders are analyzed by interviews, moreover, a structural social network model containing the nodes, relationship and centrality indicators were established for understanding the mechanism and complexity of food waste management. At last, the policy implications are put forward according to the modelling analysis.

\section{Materials and methods}

\subsection{Stakeholder analysis}

SA method follows three steps: 1) identifying stakeholders; 2) categorizing stakeholders; and 3) investigating stakeholders to know their properties (Grimble and Wellard, 1997; Reed et al.,
2009). The first interviewees' list of stakeholders was created following suggestions given by the experts in the field of municipal solid waste management, and the interviewees' list was upgraded when more investigations had been done. Finally, twenty-three stakeholders were included in this study (details of the interviewees are shown in Supplementary material, S1); the name, symbol, abbreviation and classification of each stakeholder are shown in Table 1. We classified these stakeholders into five categories according to their social roles, named administration, state-owned enterprise, private enterprise, research institute, social organizations and other types.

For better understanding the food waste material flow in an industrial ecology perspective, we divided the stakeholders into four types according to their position of the industrial chain in the food waste management system. Fig. 1 shows the material flow and the industrial chain of food waste management system, along with the position or impacts of different stakeholders.

The specific profiles for different stakeholders are described as follows:

[f]

a Administration: MCCAE is the major administrative department in charge of the planning, construction, and supervision of waste treatment facilities. CAC is in charge of MSW collecting and instructing source separation in community. DSMO is the superior department of CAC, who communicates with MCCAE about the affairs of waste management. $A B$ and BMBL\&F are government department who approve the utilization of final compost products. VMC is the representative of farmers, who are important ultimate users of compost.

b State-owned enterprise: ESEG is a state-owned enterprise closely related to MCCAE. It is responsible for collecting and transporting municipal solid waste to the MSW facilities. The responsibility of $\mathrm{CP}$ is biological treatment of the organic waste in Beijing under the building operation transfer mode (BOT); CP is highly relied on the financial subsidies from MCCAE and is governed by ESEG. TV is a state-owned media. It is involved in publicity for compost products around the nation. Enterprises invest in LP, similar to CP, which is attached to ESEG, whose subsidiary is responsible for the operation and supervision of LP.

c Private Enterprise: IP, which is supervised by MCCAE and ESEG, refers to investment and operation in enterprises. FP encompasses those companies that produce organic fertilizer, demand source-sorted food waste, and have the capacity to improve the quality of fertilizer. CFP refers to companies that only provide chemical fertilizers and which are against the production of organic fertilizer. SNB possibly uses final compost products for seedling. LEC is an emerging enterprise focusing on forestry and landscaping construction with most of the engineering projects from BMBL\&F. NM is the propagandist for science popularization to raise environmental awareness among the young and middleaged. MSC refers to emerging enterprises that provide solutions to waste management and establish connections among stakeholders.

d Research institute: MR concentrates on current planning and policy and aims at identifying proper solutions through research and analysis. TR is responsible for exploring the best compost conditions, developing compost facilities, and improving the production speed and quality of compost.

e Social organization: The main consideration for an NGO is the resource utilization of waste and the reduction of waste. It also concerns the promotion of household food waste classification and compost application, urging the government to adopt environmentally friendly measures. 
Table 1

Categories and identification of the stakeholders.

\begin{tabular}{|c|c|c|c|c|c|}
\hline Category & No. & Abbrev. & Stakeholders & Node $(\mathrm{N})$ & Social roles \\
\hline \multirow[t]{6}{*}{ Upstream } & 1 & MCCAE & Beijing Municipal Commission of City Administration and Environment & $\mathrm{N}_{\mathrm{u}-\mathrm{MCCAE}}$ & Administration \\
\hline & 2 & ESEG & Beijing Environment Sanitation Engineering Group Co., Ltd & $\mathrm{N}_{\mathrm{u}-\mathrm{ESEG}}$ & State owned enterprise \\
\hline & 3 & DSMO & District of Street Management Office & $\mathrm{N}_{\mathrm{u}-\mathrm{DSMO}}$ & Administration \\
\hline & 4 & CAC & Community Administrate Committee & $\mathrm{N}_{\mathrm{u}-\mathrm{CAC}}$ & Administration \\
\hline & 5 & CMC & Community Management Company & $\mathrm{N}_{\mathrm{u}-\mathrm{CMC}}$ & Private enterprise \\
\hline & 6 & $\mathrm{R}$ & Residents & $\mathrm{N}_{\mathrm{u}-\mathrm{R}}$ & Other group \\
\hline \multirow[t]{3}{*}{ Midstream } & 7 & $\mathrm{CP}$ & Off-site Compost Plant & $\mathrm{N}_{\mathrm{m}-\mathrm{CP}}$ & State owned enterprise \\
\hline & 8 & FP & Fertilizer Plant: producing organic fertilizer & $\mathrm{N}_{\mathrm{m}-\mathrm{FP}}$ & Private enterprise \\
\hline & 9 & CFP & Chemical Fertilizer Plant: producing chemical fertilizer & $\mathrm{N}_{\mathrm{m}-\mathrm{CFP}}$ & Private enterprise \\
\hline \multirow[t]{6}{*}{ Downstream } & 10 & $\mathrm{AB}$ & Beijing Agricultural Bureau & $\mathrm{N}_{\mathrm{d}-\mathrm{AB}}$ & Administration \\
\hline & 11 & BMBL\&F & Beijing Municipal Bureau of Landscape and Forestry & $\mathrm{N}_{\mathrm{d}-\mathrm{BLF}}$ & Administration \\
\hline & 12 & SNB & Seedling and Nursery Base & $\mathrm{N}_{\mathrm{d}-\mathrm{SNB}}$ & Private enterprise \\
\hline & 13 & $\mathrm{~F}$ & Farmers & $\mathrm{N}_{\mathrm{d}-\mathrm{F}}$ & Other group \\
\hline & 14 & LEC & Landscaping Engineering Company & $\mathrm{N}_{\mathrm{d}-\mathrm{LEC}}$ & Private enterprise \\
\hline & 15 & VMC & Village Management Committee & $\mathrm{N}_{\mathrm{d}-\mathrm{VMC}}$ & Administration \\
\hline \multirow[t]{8}{*}{ Other group } & 16 & TV & Television media & $\mathrm{N}_{\mathrm{o}-\mathrm{TV}}$ & State owned enterprise \\
\hline & 17 & NM & Network Media & $\mathrm{N}_{\mathrm{O}-\mathrm{NM}}$ & Private Enterprise \\
\hline & 18 & LP & Landfill Plant & $\mathrm{N}_{\mathrm{O}-\mathrm{LP}}$ & State owned enterprise \\
\hline & 19 & IP & Incineration Plant & $\mathrm{N}_{\mathrm{O}-\mathrm{IP}}$ & Private enterprise \\
\hline & 20 & MSC & MSW Management Service Company & $\mathrm{N}_{\mathrm{O}-\mathrm{MSC}}$ & Private enterprise \\
\hline & 21 & MR & MSW Management Researcher & $\mathrm{N}_{\mathrm{O}-\mathrm{MR}}$ & Research institute \\
\hline & 22 & TR & MSW Technology Researcher & $\mathrm{N}_{\mathrm{O}-\mathrm{TR}}$ & Research institute \\
\hline & 23 & NGO & Environmental Protection Non-government Organization & $\mathrm{N}_{\mathrm{O}-\mathrm{NGO}}$ & Social organization \\
\hline
\end{tabular}

The abbreviations of different stakeholders are shown in Table 1.

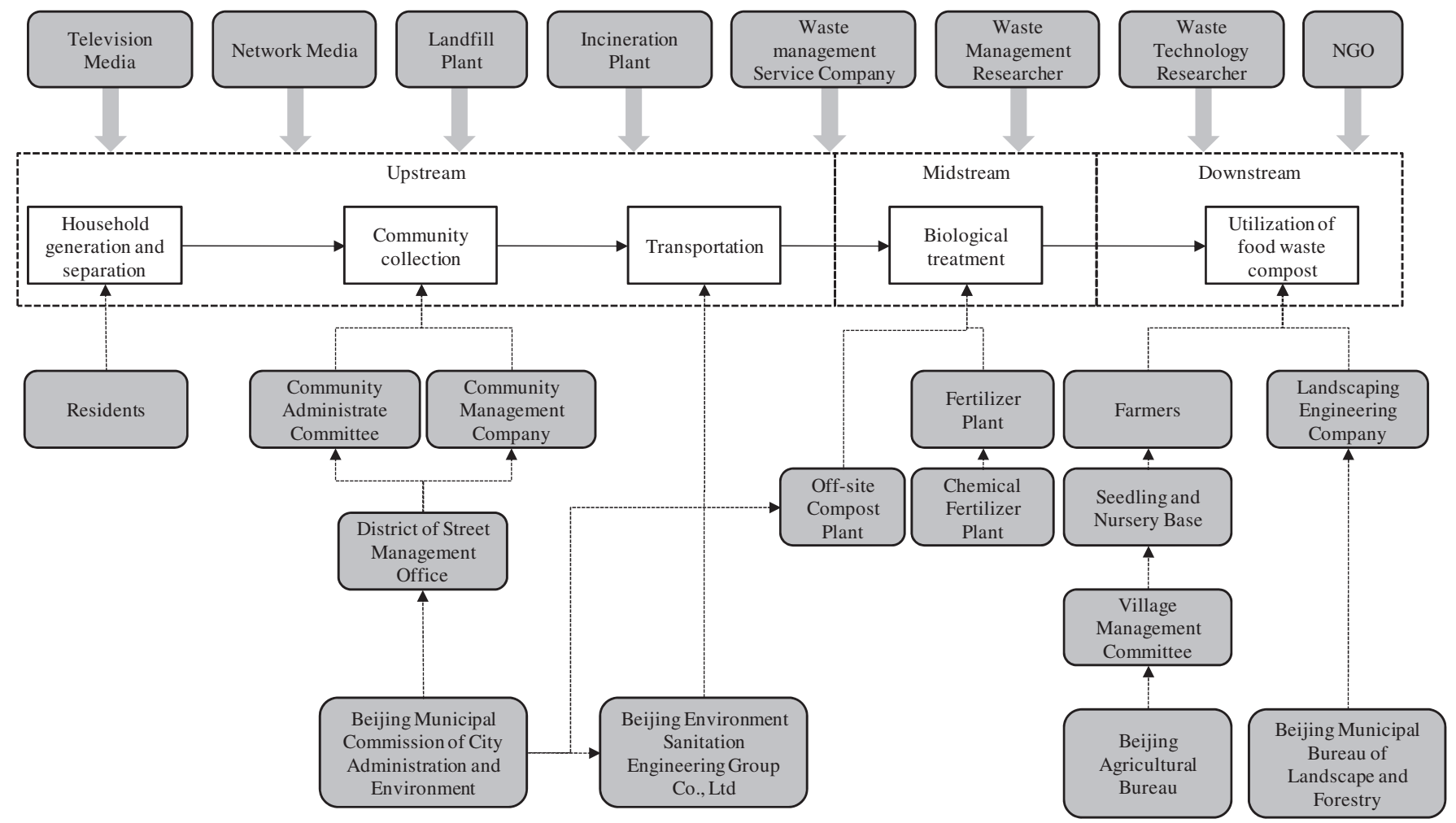

Fig. 1. The industrial chain and related stakeholders in food waste management.

f Other groups: $\mathrm{R}$ is the performer of source-sorted food waste, situated at the front of the industry chain. $\mathrm{F}$ is the receiver of final compost products and also stands at the end of the chain.

\subsection{Social network model}

Social network analysis (SNA) is a kind of sociological research method by models and parameters, Indicators of density, node degree, distance and centrality are always used in order to understand the structure and properties characteristics of the social network (Wasserman and Faust, 1994). The data were obtained from interviews and investigations, and then the data were processed with UCINET software (version 6.237) to calculate the indicators and draw the network structures (Borgatti et al., 2002). 


\subsubsection{Density}

Density (D) refers to the ratio of what a stakeholder receives and the sum of the total networks, including self-relations. The direction assignment value formula is as Formula (1). When Ego-centric density (DE) is standardized, self-relations are not included in the network as Formula (2).

$\mathrm{D}=\frac{\sum L_{w}}{N \times N}$

$\mathrm{DE}=\frac{\sum L_{w}}{N \times(N-1)}$

Where, $L_{w}$ is the assignment value of all relations; $\mathrm{N}$ is the stakeholder number (node number), $\mathrm{N}^{*} \mathrm{~N}$ refers to the size of the whole network, $\mathrm{N}^{*}(\mathrm{~N}-1)$ does not include the size of the self-relations network.

\subsubsection{Node degree}

Node degree shows the total level of relationships for a stakeholder $\left(N_{i}\right)$ and others. Concerning the directions of these relationship, there are node in-degrees (in-degree, $D_{i n, N i j}$ ) and node out-degrees (out-degree, $D_{\text {out }, N j i}$ ). The former refers to received relations, a degree of popularity; the latter refers to sending relations, a degree of positivity (Wasserman and Faust, 1994). Currently, two computing methods are available for measuring indegree and out-degree in assigning value direction relations. One is the sum and the other is the average (Knoke and Yang, 2008). Since values assigned in this case are small and of few levels, the sum formula is used in this case (Formula (3)).

$D_{(N i)}=\sum_{i \neq j}^{N} D_{i n+N i j}+\sum_{i \neq j}^{N} D_{o u t+N j i}$

Where, $D_{\text {in, Nij }}$ is the node in-degree; $D_{\text {out, Nji }}$ is the node out-degree; $\mathrm{N}$ is the numbers of stakeholders; $i$ is the numbering of examined stakeholder; $j$ is the numbering of relative stakeholders.

\subsubsection{Distance}

Distance means the minimum distance between two stakeholders, who are related to the other as long as one side is connected in a non-direction relation. Some scholars suggest that the distance can be measured by path length and path value (Yang and Hexmoor, 2004; Yang and Knoke, 2001). However, most researchers choose to calculate it using binary data. In this research, the assignment value data will convert to binary data for distance and closeness centrality (CC) because of the smaller assigned value.

\subsubsection{Centrality indices}

Three different measures of node centrality have been widely applied: centrality degree (CD), closeness centrality (CC), and betweenness centrality (BC) (Freeman, 1977, 1979). Degree centrality (DC) is the direct total relations between a node and others (Formula (4)). In a directed assignment value relation with both a sent relation and a received relation, only a one-way relation is counted, coming from the maximum of the assignment value relation, then the sum is calculated. Closeness centrality (CC) quantifies how short the minimal paths from a given node to others are (Wasserman and Faust, 1994). The standardized index for a node $_{i}\left(C_{i}\right)$ is expressed as follows (Navia et al., 2010), see Formula (5). Betweenness centrality (BC) refers to the extent to which other stakeholders rely on the minimum distance between two stakeholders in a network. It is a significant index during networkcontrol communication and resource flow. The standardized index for a node ${ }_{i}\left(B C_{i}\right)$ is (Borgatti et al., 2002; Navia et al., 2010; Wasserman and Faust, 1994), see Formula (6).

$D C_{i}=\frac{\sum_{j=1}^{N} x_{i j}}{N-1}, i \neq j$

$C C_{i}=\frac{N-1}{\sum_{j=1}^{N} d_{i j}}, i \neq j$

$B C_{i}=\frac{2 \times \sum_{j \leq k} g_{j k}(i) / g_{j k}}{(N-1)(N-2)}, i \neq j \& k$

Where, $x_{i j}$ is the total relations of a stakeholder; $d_{i j}$ is distance; $g_{j k}$ is the number of equally shortest paths between nodes $\mathrm{j}$ and $\mathrm{k}$; $\mathrm{N}$ is the stakeholder number (node number); $\mathrm{I}, \mathrm{j}$, k refers to the numbering of different stakeholders.

\subsection{Studied case and data source}

Beijing, the capital of China, was chosen as the studied case. In 2013, Beijing had a population around 20 million, and had a large amount of municipal solid waste generation as many as 6.67 million tons per year. As for treatments percentage, $90 \%$ of the total goes to landfills, following by off-site compost and incineration, amounting to $8 \%$ and $2 \%$, respectively (Beijing Bureau of Statistics, 2014). The food waste disposed to landfills accounts for more than $60 \%$ (Zhou et al., 2011). The generation of different district in Beijing and the compositions of the municipal solid waste were shown in Supplementary material, S2. Beijing was one of the pilot cities exploring the approaches for food waste source separation. An assumed program of recycling and composting household food is studied in this paper, to better understanding who is the influencers and opposers and how they will behave in the program. The basic storyline of this program is that household food waste should be source separated in the communities, then compost them in the biological treatment facilities and the compost is utilized as fertilizer for cropland, garden and green land.

A description of the scoring of the questionnaire results is shown in Table 2; the questionaire system was partly referenced by Caniato et al. (2014), and some modifications were made to meet the demand of analyzing the food waste management system (detail questionaire is shown in Supplementary material, S3). Based on snowball sampling, they are interviewed either personally or via telephone. Only one representative person, who is the leader of his organization, was interviewed for each category of stakeholder, except resident and farmers. Two persons were interviewed from residents (middle-aged adult and youth) and farmers (individual farmer and farmer worked for marketing cooperatives). Quantitative data were averaged, while qualitative data was composited.

\section{Results}

\subsection{Interest and power of stakeholders}

The interest-power relationship of stakeholders is shown in Fig. 2. According to interviews of different stakeholders, MCCAE, who is directly in charge of the food waste collecting and treatment, has the highest power and maximum interest to promote the food waste recycling and composting. The local governments (CAC and DSMO) and two private enterprises (CAC and MSC) also can be the key players of food waste recycling and composting because all of them have comparative higher power and interest. In addition, three administrating departments and two state-owned enterprises show minimum interest, although they have enough power to influence the food waste recycling. For instance, $A B$ and 
Table 2

Questionnaire and scoring of the properties of different stakeholders.

\begin{tabular}{|c|c|}
\hline Properties & Scoring ${ }^{\mathrm{a}}$ \\
\hline Interest: describes the degree of stakeholders' interest. & $\begin{array}{l}\text { [5.] } \\
\text { 1. No or minimum interest }(1-2) \\
\text { 2. Low interest }(3-4) \\
\text { 3. General interest }(5-6) \\
\text { 4. High interest }(7-8) \\
\text { 5. Maximum interest }(9-10)\end{array}$ \\
\hline $\begin{array}{l}\text { Power: describes the capacity to promote the program } \\
\text { and gathering other stakeholders. }\end{array}$ & $\begin{array}{l}\text { [5.] } \\
\text { 1. Very low power }(1-2) \\
\text { 2. Low power }(3-4) \\
\text { 3. General knowledge }(5-6) \\
\text { 4. High power }(7-8) \\
\text { 5. Very High power }(9-10)\end{array}$ \\
\hline $\begin{array}{l}\text { Knowledge: describes the self-reported level of } \\
\text { knowledge of the interviewed. }\end{array}$ & $\begin{array}{l}\text { [5.] } \\
\text { 1. Very incomplete knowledge (1-2) } \\
\text { 2. Incomplete knowledge }(3-4) \\
\text { 3. General knowledge }(5-6) \\
\text { 4. Complete knowledge }(7-8) \\
\text { 5. Very complete knowledge (9-10) }\end{array}$ \\
\hline $\begin{array}{l}\text { Attitude: describes the level of the interviewee's } \\
\text { confidence of the program. }\end{array}$ & $\begin{array}{l}\text { [7.] } \\
\text { 1. Strongly positive } \\
\text { 2. Positive } \\
\text { 3. Slightly positive } \\
\text { 4. Neutral } \\
\text { 5. Slightly negative } \\
\text { 6. Negative } \\
\text { 7. Strongly negative }\end{array}$ \\
\hline $\begin{array}{l}\text { Information: describes the difficulties and accuracy of } \\
\text { obtain the information. }\end{array}$ & $\begin{array}{l}\text { [5.] } \\
\text { 1. Very easy obtain and high accuracy }(1-2) \\
\text { 2. Easy obtain and considerable accuracy }(3-4) \\
\text { 3. Normal obtain and moderate accuracy }(5-6) \\
\text { 4. Difficult obtain and poor accuracy }(7-8) \\
\text { 5. Very difficult obtain and very poor accuracy }(9-10)\end{array}$ \\
\hline $\begin{array}{l}\text { Interaction: describes the level of interaction between } \\
\text { the stakeholder interviewed and other stakeholders }\end{array}$ & $\begin{array}{l}3 \text { levels (no recoding) } \\
\text { [3.] } \\
\text { 1. No interaction } \\
\text { 2. Occasional interaction } \\
\text { 3. Frequent interaction }\end{array}$ \\
\hline
\end{tabular}

a Five to seven levels, original scoring from 1 to 10.

BMBL\&Fare in charge of the agricultural and garden affairs of Beijing, and they can determine whether or not utilizing the food waste compost. Four stakeholders (FP, R, TV, NGO, NM) show very high level of interest on food waste composting, but they do not have a high power to implement this. However, this group of stakeholders is very important in promoting food waste recycling, e.g. TV and NM can contribute on broadcasting the necessity and knowledge of source separation; while resident (R) and NGO can be key operator when the food waste recycling program is start up. Other stakeholders, such as CFP, LEC and SNB, have minimum efforts on the food waste recycling; they act as participants but are not very vital to determine anything in food waste recycling.In the perspective of industrial ecology, the stakeholders are classified into upstream midstream and downstream and other sectors in food waste management. LP and IP show some degree of interest, although there is potential competition between composting plants and them. As we know, both of these waste treatment facilities are financially relied on the quantities of waste they treated, thus their subsidies will be less when the food waste recycling program starts up. However, they will benefit from removing of the food waste from the material stream to landfill and incinerators. Fewer burdens on leachate and odor treatment and higher heat values of incinerated waste could be expected, which may result in lowering the operating cost of landfill and incinerators.

As a general trend, stakeholders in the upstream sectors show greater influence on food waste recycling program, however, stakeholders in the downstream show much less interest on it. If the knowledge factor of stakeholders is examined, we found that the knowledge level of the downstream stakeholders is comparatively lower than others, they worry about the fertilizer effect, odor and hazard components of the compost transforming from household food waste. Insufficient knowledge also results in the attitude toward food waste recycling and composting program by different stakeholders. Different from the indicator of interest, attitude indicates the confidence in the food waste recycling and composting program by different stakeholders. Fig. 3 demonstrates that most of the stakeholders have positive attitudes, aside from CP, CFP and LEC. However, cost may be another factor that affecting the stakeholder's attitude. For example, the CFP and LEC both believe that utilized the food waste compost will increase their operating cost, e.g. landscape engineering company (LEC) thought that using food waste composting will pay more on labors comparing to use liquid nutrient, according to our investigation. 


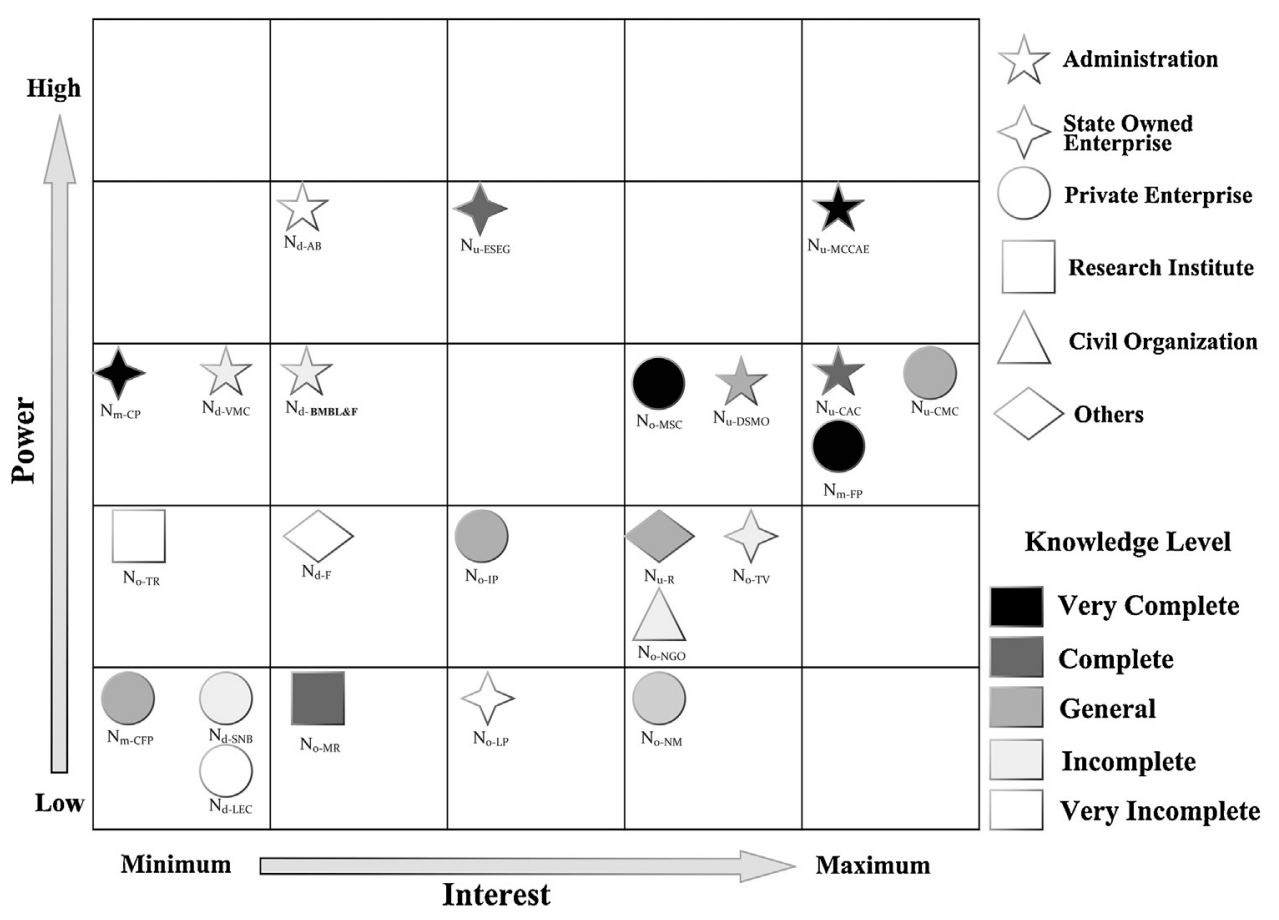

Fig. 2. Levels of interest power and knowledge of different stakeholders in food waste recycling program.

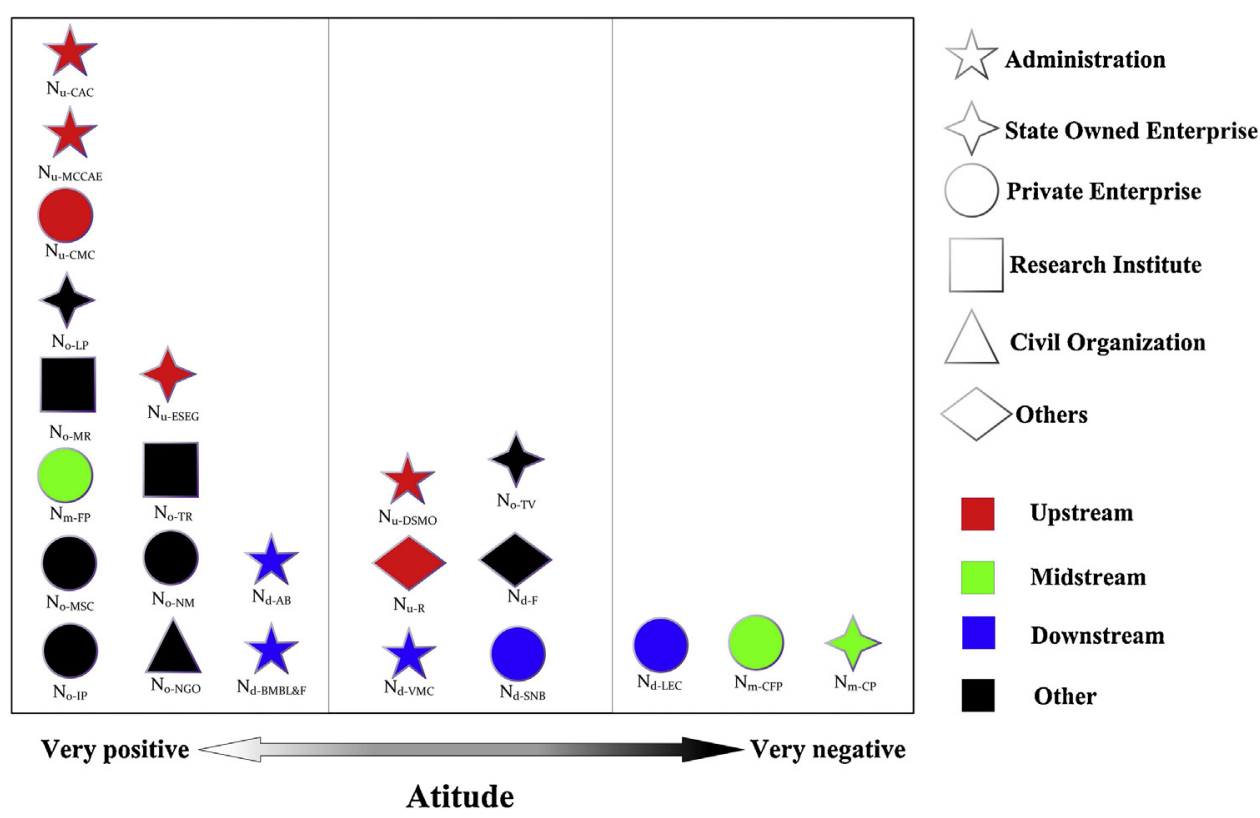

Fig. 3. Levels of attitude of different stakeholders in food waste recycling program.

\subsection{Information accuracy and sharing of stakeholders}

Fig. 4 shows a trend that the easier it is to collect accurate information, the higher the degree of sharing. However, there are two exceptional cases: when information is easily collected but the willingness to share is lacking and when individuals have limited information but are eager to share. On one hand, the reviewees affiliated to research institutes in Beijing (MR and TR) lack approach and motivation to share the information in the field of waste treatment and management. On the other hand, the local and grass-root level governors with limited information but like to share, such as the DSMO (sub-district office) and CAC (community administrate committee). Despite the incomplete information it obtains, it tends to share it with others. It shows a disconnection between scientific researches and the practical demands in some extent in the research \& development activities of waste management in China. In addition, we found that it is essential to improve the knowledge of the grass-root governors, who most closely contact with the residents, to avoid misunderstanding of the food waste recycling program and help and motivate the residents to practice food waste source separation. The television video media (TV) and internet media (NM) did not show a much higher level of information accuracy than the residents; however, the sharing motivation of NM is higher than TV, which indicates that the internet media could be a key player to broadcast the information of food waste source separation and recycling. 


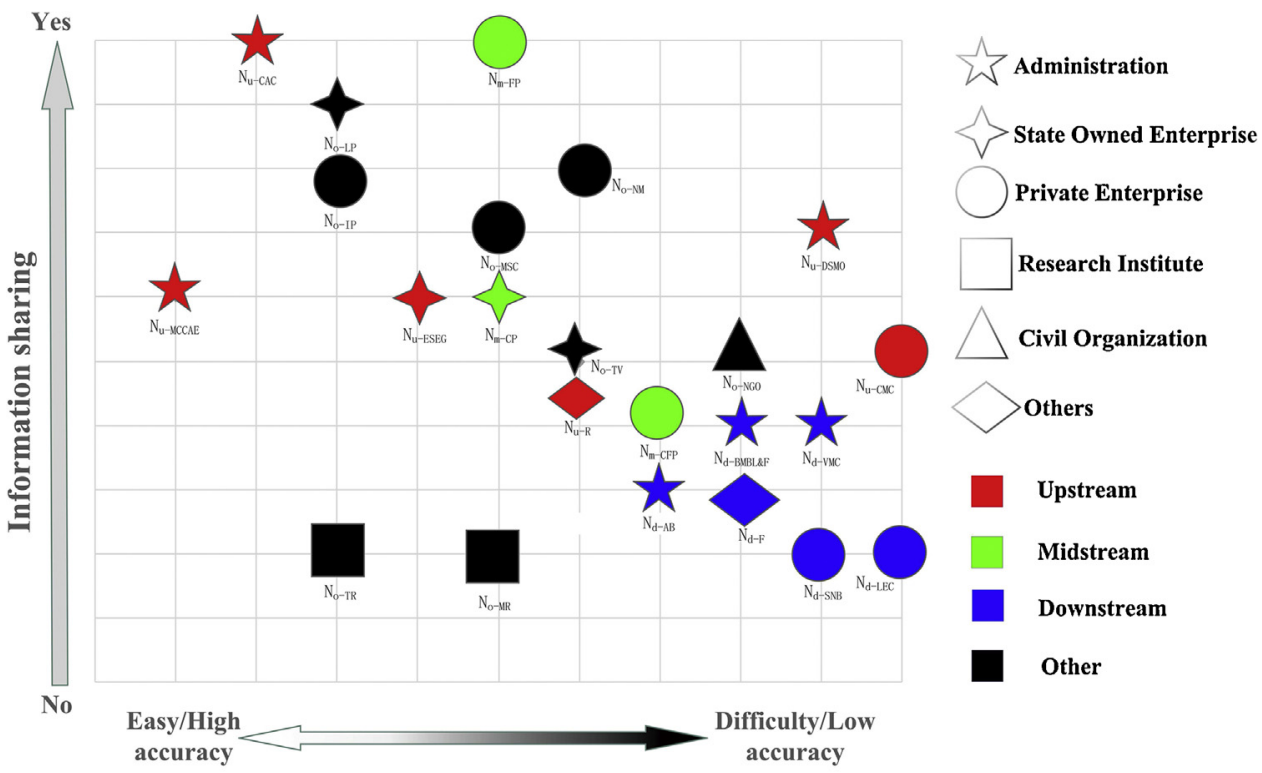

Information collection level of difficulty and accuracy

Fig. 4. Levels of information sharing and accuracy of different stakeholders in food waste recycling program.

\subsection{Social network analysis}

According to results of social network models(see Table 3), the density and node degree of NGO, resident (R), CP and MCCAE are relatively high, indicating their high popularity. Residents are practitioners of source separation of household food waste, which is why other stakeholders always contact with them for publicity and education. NGO acts as a bridge of different stakeholders in promoting food waste recycling. They always communicate with the government, practice programs in communities, monitor the efficacy of the on-going program and educate the public, to achieve their own social values. MCCAE is the key department who in charge of the municipal solid waste management affairs in Beijing, therefore, they became the central of the social networks in the food waste recycling program. In contrast, when assignment value data are converted into binary, $D_{i n, N i j}$ of $N_{o-N G O}, N_{o-M R}$ and $N_{m-C P}$ are higher than others, so that $D_{i n}$ and $N_{i j}$ of $N_{m-C P}$ exceed $D_{i n}$ and $N_{i j}$ of $N_{u-R}$. This circumstance shows that information is sometimes omitted during the binary conversion process; but a lower assignment value makes little difference. The same results in an assignment value and binary data that $D_{o u t, N j i}$ of $N_{u-M C C A E}, N_{m-F P}, N_{o-M S C}$ are higher than others, revealing that they are the prime movers for food waste recycling and composting. It shows weak social network relations, in some extent, according to the results of $\mathrm{D}(\%)$ and $\mathrm{DE}(\%)$. The density of the assignment value and binary are $48 \%$ to $51 \%$ and $37 \%$ to $39 \%$, respectively, especially of $N_{d-A B}, N_{d-B M B L \& F}$ and $N_{d-V M C}$ (Table 3).

Regarding the centrality indicators of the social network model (see Fig. 5), $N_{m-F P}$ tops the list with a DC value of $86.36 \%$, followed by $N_{o-M S C}$ with $81.82 \% . N_{u-M C C A E}, N_{o-T R}$ and $N_{o-M R}$ come in third. The CC values of these stakeholders fluctuate from $22.68 \%$ to $35.48 \%$. The CC values are low for $N_{d-B M B L \& F}, N_{d-L E C}, N_{o-I P}, N_{d-A B}$, and $N_{u-E S E G}$, most of which are downstream stakeholder group. The $B C$ value of $N_{m-F P}$ is the highest with $27.00 \%$, followed by $N_{o-M S C}$ with $18.08 \%$. The results of centrality indicators indicate that: 1) MCCAE, NGO and the research institutes (MR and TR) have the highest level of connections with other stakeholders; 2) communication is lacking among downstream, midstream and upstream stakeholders, and some key stakeholder like ESEG (upstream) does not interact frequently with other stakeholders; 3 ) some stakeholders can serve as an important bridge between different stakeholders, e.g. MSC and FP could be very important to connect different stakeholders in the food waste recycling and composting program, even they did not have enough sufficient power to promote it. The relation network results coincide with the stakeholder analysis (interest and power) of stakeholders, as the stronger the interest, the denser the relation network.

\section{Discussion and conclusions}

Although there are lots of studies demonstrated that the food waste recycling and composting can significantly improve the systemic efficacy of the municipal solid waste management system, by using life cycle analysis and cost benefit analysis (Beattie, 2014; Khoo et al., 2010; Kim and Kim, 2010), the implementation in China remains difficulties. It is mainly because of the complexity of stakeholders' behavior and reaction of human society, which means that there are disconnection and lacking cooperation among stakeholders. To understand the internal mechanism of food waste management, this paper provides a method integrated stakeholder analysis and social network models, presenting a quantitative and agent based informatics within material flows.

Main finding of this paper includes:

Firstly, according to the results of SA, more than a half of the stakeholders lack motivation of food waste recycling and composting, and the stakeholders with maximum interest do not have sufficient power to make any changes of the current system. This imbalance of the power and interest among the stakeholders resulted in the fact that only a few of governmental department promoted the food waste recycling program alone, without the cooperation with other powerful department. Secondly, the department of MCCAE is certainly the key player in promoting food waste recycling due to the high interest, power and degree of centrality. However, MCCAE is located in the upstream of food waste recycling, i.e. it is only responsible for the collecting transporting and treating of the food waste. The key players (or promotors) in midstream and downstream of food waste management do not exist according to our study. In perspective of industrial ecology, the internal chains between different sectors were broken. Therefore, some incentive policies can be designed to motivate the potential key players in 

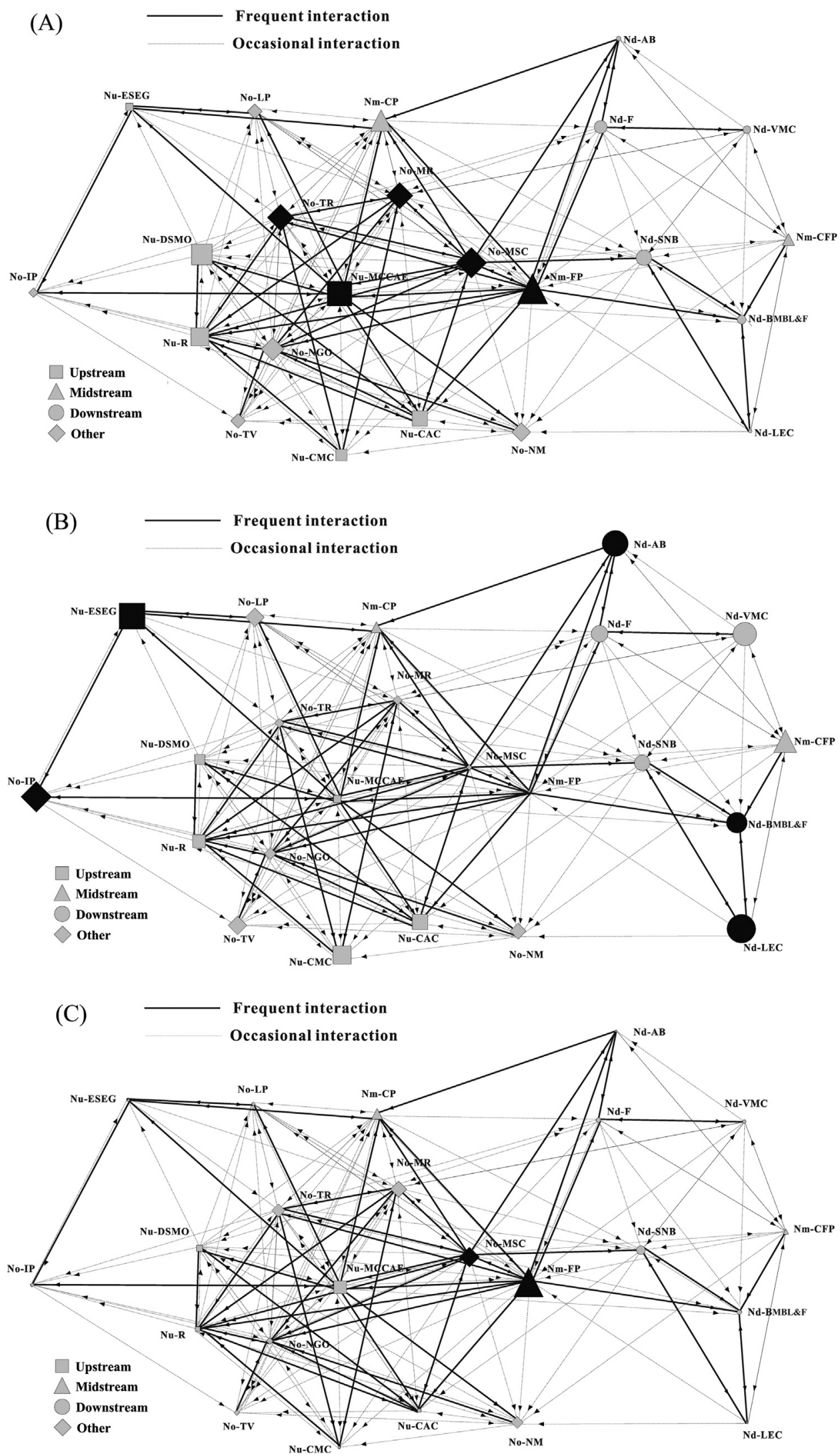

Fig. 5. The social network structure and centrality of different stakeholders in food waste recycling program: (A) degree of centrality (DC); (B) closeness centrality (BC); (C) betweeness centrality (CC). 
Table 3

Node degree, density and centrality indicators of different stakeholders (\%).

\begin{tabular}{|c|c|c|c|c|c|c|c|c|c|c|c|}
\hline \multirow[t]{2}{*}{ Nodes } & \multicolumn{2}{|l|}{$\mathrm{D}_{\mathrm{in}, \mathrm{Nij}}$} & \multirow{2}{*}{$\frac{\mathrm{D}_{\text {out,Nji }}}{\text { original }}$} & \multicolumn{2}{|l|}{ D } & \multirow{2}{*}{$\frac{\mathrm{DE}}{\text { binary }}$} & \multicolumn{2}{|l|}{ DC } & \multirow{2}{*}{$\frac{\mathrm{CC}}{\text { binary }}$} & \multicolumn{2}{|l|}{$\mathrm{BC}$} \\
\hline & original & binary & & binary & original & & original & binary & & binary & binary \\
\hline $\mathrm{N}_{\mathrm{u}-\mathrm{MCCAE}}$ & 14.5 & 12.0 & 23.0 & 16.0 & 7.09 & 5.29 & 7.41 & 5.53 & 72.73 & 35.48 & 15.00 \\
\hline $\mathrm{N}_{\mathrm{u}-\mathrm{ESEG}}$ & 8.0 & 5.0 & 10.0 & 6.0 & 3.40 & 2.08 & 3.56 & 2.17 & 31.82 & 25.29 & 1.37 \\
\hline $\mathrm{N}_{\mathrm{u}-\mathrm{DSMO}}$ & 11.5 & 10.0 & 12.0 & 10.0 & 4.44 & 3.78 & 4.64 & 3.95 & 63.64 & 30.56 & 6.96 \\
\hline $\mathrm{N}_{\mathrm{u}-\mathrm{CAC}}$ & 14.5 & 10.0 & 11.0 & 7.0 & 4.82 & 3.21 & 5.04 & 3.36 & 50.00 & 30.56 & 6.06 \\
\hline $\mathrm{N}_{\mathrm{u}-\mathrm{CMC}}$ & 10.5 & 9.0 & 6.0 & 5.0 & 3.12 & 2.65 & 3.26 & 2.77 & 40.91 & 28.21 & 0.61 \\
\hline $\mathrm{N}_{\mathrm{u}-\mathrm{R}}$ & 18.0 & 10.0 & 7.5 & 11.0 & 4.82 & 3.97 & 5.04 & 4.15 & 59.09 & 30.99 & 3.84 \\
\hline $\mathrm{N}_{\mathrm{m}-\mathrm{CP}}$ & 16.5 & 12.0 & 10.0 & 9.0 & 5.01 & 3.97 & 5.24 & 4.15 & 63.64 & 31.88 & 11.29 \\
\hline $\mathrm{N}_{\mathrm{m}-\mathrm{FP}}$ & 10.5 & 10.0 & 26.0 & 16.0 & 6.90 & 4.91 & 7.21 & 5.14 & 86.36 & 35.48 & 27.00 \\
\hline $\mathrm{N}_{\mathrm{m} \text {-CFP }}$ & 4.5 & 5.0 & 9.0 & 8.0 & 2.55 & 2.46 & 2.67 & 2.57 & 40.91 & 26.19 & 3.16 \\
\hline $\mathrm{N}_{\mathrm{d}-\mathrm{AB}}$ & 7.5 & 5.0 & 6.0 & 4.0 & 2.55 & 1.70 & 2.67 & 1.78 & 27.27 & 25.29 & 0.90 \\
\hline $\mathrm{N}_{\mathrm{d}-\mathrm{BMBL} \& \mathrm{~F}}$ & 12.0 & 8.0 & 3.0 & 2.0 & 2.84 & 1.89 & 2.96 & 1.98 & 36.36 & 22.68 & 3.16 \\
\hline $\mathrm{N}_{\mathrm{d}-\mathrm{SNB}}$ & 10.5 & 9.0 & 7.0 & 5.0 & 3.31 & 2.65 & 3.46 & 2.77 & 50.00 & 27.16 & 9.92 \\
\hline $\mathrm{N}_{\mathrm{d}-\mathrm{F}}$ & 11.0 & 8.0 & 6.5 & 7.0 & 3.31 & 2.84 & 3.46 & 2.96 & 45.45 & 28.21 & 4.80 \\
\hline $\mathrm{N}_{\mathrm{d}-\text { LEC }}$ & 5.0 & 3.0 & 7.0 & 5.0 & 2.27 & 1.51 & 2.37 & 1.58 & 22.73 & 23.66 & 5.76 \\
\hline $\mathrm{N}_{\mathrm{d}-\mathrm{VMC}}$ & 5.0 & 4.0 & 8.0 & 7.0 & 2.46 & 2.08 & 2.57 & 2.17 & 31.82 & 26.51 & 3.07 \\
\hline $\mathrm{N}_{\mathrm{o}-\mathrm{TV}}$ & 10.0 & 10.0 & 4.0 & 3.0 & 2.65 & 2.46 & 2.77 & 2.57 & 45.45 & 27.16 & 1.08 \\
\hline $\mathrm{N}_{\mathrm{O}-\mathrm{NM}}$ & 9.5 & 9.0 & 7.0 & 6.0 & 3.12 & 2.84 & 3.26 & 2.96 & 54.55 & 27.16 & 7.37 \\
\hline $\mathrm{N}_{\mathrm{O}-\mathrm{LP}}$ & 11.5 & 10.0 & 8.0 & 7.0 & 3.69 & 3.21 & 3.85 & 3.36 & 45.45 & 29.73 & 2.25 \\
\hline $\mathrm{N}_{\mathrm{O}-\mathrm{IP}}$ & 7.5 & 6.0 & 4.0 & 4.0 & 2.17 & 1.89 & 2.27 & 1.98 & 31.82 & 23.91 & 0.58 \\
\hline $\mathrm{N}_{\mathrm{o}-\mathrm{MSC}}$ & 12.0 & 7.0 & 27.0 & 18.0 & 7.37 & 4.73 & 7.71 & 4.94 & 81.82 & 34.38 & 12.07 \\
\hline $\mathrm{N}_{\mathrm{O}-\mathrm{MR}}$ & 14.0 & 13.0 & 19.0 & 14.0 & 6.24 & 5.10 & 6.52 & 5.34 & 72.73 & 35.48 & 18.08 \\
\hline $\mathrm{N}_{\mathrm{o}-\mathrm{TR}}$ & 11.5 & 10.0 & 19.0 & 14.0 & 5.77 & 4.54 & 6.03 & 4.74 & 72.73 & 33.85 & 6.37 \\
\hline $\mathrm{N}_{\mathrm{O}-\mathrm{NGO}}$ & 19.5 & 12.0 & 15.0 & 13.0 & 6.52 & 4.73 & 6.82 & 4.94 & 63.64 & 33.85 & 11.21 \\
\hline Total & - & - & - & - & 48.20 & 37.24 & 50.40 & 38.93 & - & - & - \\
\hline
\end{tabular}

the midstream and downstream of food waste management, such as subsidy for food waste recycling and mandatory utilization of such compost to urban green land. According to the BC and DC result, the stakeholders such as FP, MSC, LEC can be the potential key players. Thirdly, the overall knowledge and information about food waste recycling are not sufficient and accurate. According to the result of information collection of different stakeholders, the grass-root governments lack accurate information but the research institutes lack approach and willing to sharing their knowledge of food waste recycling. It indicates that a mechanism of conveying the accurate knowledge from scientists down to the stakeholders who practicing food waste recycling is needed.

Food waste management is one representative issue regarding to the biogeochemical cycle of urban ecosystem. Different from the natural ecosystem, material flows in urban ecosystem are dominated by the behaviors and interactions among different group of people, i.e. stakeholders. This results in the complexity of studying the urban ecosystems. There are various models were integrated to simplify the complexity of urban ecosystem, such as life cycle analysis, cost benefit analysis, material flow analysis(Vadenbo et al., 2014). This study demonstrates that the SA and SN models could also be applied and be integrated to understanding the processes and the internal mechanism of the sustainable material flows in urban ecosystems. In addition, the SA and SN models can be used as a useful tool for the policy makers of municipal solid waste management. The interest, power, attitude and knowledge of different stakeholders and their social networks could be examined in advance of making policies or starting up recycling programs. It could be helpful to find out the key players or motivate other players.

\section{Acknowledgements}

Project supported by the National Natural Science Foundation of China (Grant No. 71533004) and the China National Major Science and Technology Program for Water Pollution Control and Treatment (2014ZX07201). Here, we also want to commemorate an outstanding ecologist - Professor Rusong Wang, who gave us a lot of helpful ideas of this article.

\section{Appendix A. Supplementary data}

Supplementary data associated with this article can be found, in the online version, at http://dx.doi.org/10.1016/j.ecolmodel.2016. 06.006 .

\section{References}

Barnes, J., 1954. Class and committees in a Norwegian Island parish. Human Relations 7, 39-58.

Beattie, A., 2014. Cost-benefit analysis of food-waste composting program at UMM. Sch. Horiz.: Univ. Minnesota Morris Undergrad. J. 1, 1.

Beijing Bureau of Statistics, 2014. District Statistics Yearbook of Beijing. China statistics press, Beijing.

Borgatti, S.P., Everett, M.G., Freeman, L.C., 2002. Ucinet for Windows: Software for social network analysis.

Buzhdygan, O.Y., Patten, B.C., Kazanci, C., Ma, Q., Rudenko, S.S., 2012. Dynamical and system-wide properties of linear flow-quantified food webs. Ecol. Model. $245,176-184$

Caniato, M., Vaccari, M., Visvanathan, C., Zurbrügg, C., 2014. Using social network and stakeholder analysis to help evaluate infectious waste management: a step towards a holistic assessment. Waste Manage. 34, 938-951.

Caniato, M., Tudor, T., Vaccari, M., 2015. Understanding the perceptions, roles and interactions of stakeholder networks managing health-care waste: a case study of the Gaza Strip. Waste Manage. 35, 255-264.

Dell'Apa, A., Johnson, J.C., Kimmel, D.G., Rulifson, R.A., 2013. The international trade and fishery management of spiny dogfish: asocial network approach. Ocean Coast. Manage. 80, 65-72.

Emshoff, J.R., 1980. Managerial Breakthroughs: Action Techniques for Strategic Change. Amacom.

Freeman, L.C., 1977. A set of measures of centrality based on betweenness. Sociometry, 35-41.

Freeman, L.C., 1979. Centrality in social networks conceptual clarification. Soc. Netw. 1, 215-239.

Freeman, R.E., 2010. Strategic Management: A Stakeholder Approach. Cambridge University Press.

Grimble, R., Wellard, K., 1997. Stakeholder methodologies in natural resource management: a review of principles contexts, experiences and opportunities. Agric. Syst. 55, 173-193.

Harary, F., 1969. Graph Theory. Addison-Wesley, Reading, MA.

Hicks, C.C., Graham, N.A., Cinner, J.E., 2013. Synergies and tradeoffs in how managers, scientists, and fishers value coral reef ecosystem services. Glob. Environ. Change 23, 1444-1453.

Khoo, H.H., Lim, T.Z., Tan, R.B., 2010. Food waste conversion options in Singapore: environmental impacts based on an LCA perspective. Sci. Total Environ. 408, 1367-1373.

Kim, M.H., Kim, J.W., 2010. Comparison through a LCA evaluation analysis of food waste disposal options from the perspective of global warming and resource recovery. Sci. Total Environ. 408, 3998-4006. 
Knoke, D., Yang, S., 2008. Social Network Analysis. Sage.

Kuo, J.H., Tseng, H.H., Rao, P.S., Wey, M.Y., 2008. The prospect and development of incinerators for municipal solid waste treatment and characteristics of their pollutants in Taiwan. Appl. Therm. Eng. 28, 2305-2314.

Lienert, J., Schnetzer, F., Ingold, K., 2013. Stakeholder analysis combined with social network analysis provides fine-grained insights into water infrastructure planning processes. J. Environ. Manage. 125, 134-148.

Mor, S., Ravindra, K., Dahiya, R., Chandra, A., 2006. Leachate characterization and assessment of groundwater pollution near municipal solid waste landfill site. Environ. Monit. Assess. 118, 435-456.

Navia, A.F., Cortés, E., Mejía-Falla, P.A., 2010. Topological analysis of the ecological importance of elasmobranch fishes: a food web study on the Gulf of Tortugas, Colombia. Ecol. Modell. 221, 2918-2926.

Reed, M.S., Graves, A., Dandy, N., Posthumus, H., Hubacek, K., Morris, J., Prell, C., Quinn, C.H., Stringer, L.C., 2009. Who's in and why? A typology of stakeholder analysis methods for natural resource management. J. Environ. Manage. 90, 1933-1949.

Stein, C., Ernstson, H., Barron, J., 2011. A social network approach to analyzing water governance: the case of the Mkindo catchment, Tanzania. Phys. Chem. Earth 36, 1085-1092.

Tai, J., Zhang, W., Che, Y., Feng, D., 2011. Municipal solid waste source-separated collection in China: a comparative analysis. Waste Manage. 31, 1673-1682.

Vadenbo, C., Hellweg, S., Guillén-Gosálbez, G., 2014. Multi-objective optimization of waste and resource management in industrial networks-part I: model description. Resour. Conserv. Recycl. 89, 52-63.
Wang, H., Nie, Y., 2001. Municipal solid waste characteristics and management in China. J. Air Waste Manage. Assoc. 51, 250-263.

Wasserman, S., Faust, K., 1994. Social Network Analysis: Methods and Applications. Cambridge University Press.

Wilson, D.C., Rodic, L., Scheinberg, A., Velis, C.A., Alabaster, G., 2012. Comparative analysis of solid waste management in 20 cities. Waste Manage. Res. 30, 237-254

Xu, W., Zhou, C., Lan, Y., Jin, J., Cao, A., 2015. An incentive-based source separation model for sustainable municipal solid waste management in China. Waste Manage. Res. 33, 469-476.

Xu, D., Lin, Z., Gordon, M.P., Robinson, N.K., Harder, M.K., 2016. Perceived key elements of a successful residential food waste sorting program in urban apartments: stakeholder views. J. Clean. Prod. (in press).

Yang, S., Hexmoor, H., 2004. Measuring optimal connections in large networks: a new algorithm and its applications. J. Math. Sociol. 28, 197-213.

Yang, S., Knoke, D., 2001. Optimal connections: strength and distance in valued graphs. Soc. Netw. 23, 285-295.

Yang, R.J., Zou, P.X., 2014. Stakeholder-associated risks and their interactions in complex green building projects: a social network model. Build. Environ. 73, 208-222.

Zhang, D., Tan, S., Gersberg, R.M., 2010. Municipal solid waste management in China: status, problems and challenges. J. Environ. Manage. 91, 1623-1633.

Zhou, C., Hu, D., Wang, R., Liu, J., 2011. Exergetic assessment of municipal solid waste management system in south Beijing. Ecol. Complex. 8, 171-176. 